\title{
CONSCIENCIA DA FINITUDE E VALORES HUMANOS: UM ESTUDO COM IDOSOS EM INSTITUIÇÕES DE LONGA PERMANÊNCIA
}

\author{
Wanderlanya Cristina Silva de Moura ${ }^{1}$ \\ Paula Marques Lima Pessoa de Aquino² \\ Thiago Antonio Avellar de Aquino ${ }^{3}$
}

resumo

O presente estudo teve como objetivo identificar o impacto da consciência da finitude na estrutura valorativa nos idosos. Participaram do estudo 50 idosos residentes de duas Instituições de Longa Permanência para ldosos, sendo a maioria do sexo feminino (72\%), com idade média de 76 anos e majoritariamente católicos (80\%). Como instrumentos de coleta foram utilizados o Questionário de Valores Básicos (QVB), o Questionário de Sentido da Vida (QSV), a Escala de Atitudes Religiosas (EAR-20), a Escala de Percepção Ontológica do Tempo e um questionário sociodemográfico. Os resultados foram discutidos à luz da Logoterapia e Análise Existencial de Viktor Frankl, relacionando a consciência da finitude da vida com a estrutura valorativa, a percepção ontológica do tempo, a atitude religiosa e a percepção da temporalidade na busca e presença de sentido.

palavras-chave

Envelhecimento. Morte. Motivação. Idoso.

1 Graduada em Enfermagem. Mestre em Ciências das Religiões. Técnica em Enfermagem na Unidade de Pronto Atendimento Dr. Luiz Lindberg Farias. E-mail: laninhafm12@hotmail.com.

2 Graduada em Psicologia. Pós-Graduação em Neuropsicologia. Vinculada ao Laboratório de Pesquisa em Logoterapia e Análise Existencial (LAPLAE). E-mail: paulamlpda@hotmail.com.

3 Graduado em Psicologia. Doutor em Psicologia Social. Professor Associado da Universidade Federal da Paraíba, vinculado ao Departamento de Ciências das Religiões. E-mail: logosvitae@hotmail.com. 
O envelhecimento pode ser compreendido como um processo dinâmico, natural e progressivo, contínuo e gradativo, que consiste em modificações morfológicas, funcionais, bioquímicas e psicológicas determinantes da perda de capacidade de adaptação do indivíduo ao meio ambiente, ocasionando maior vulnerabilidade e maior incidência de processos patológicos que terminam por levá-lo à morte (FIGUEIREDO; TONINI, 2006). Ademais, os idosos podem ser acometidos por crises existenciais (SILVA; ALVES, 2007), tendo em conta que a proximidade da morte pode levá-los a uma reflexão valorativa da existência, sobretudo quando se encontram em Instituições de Longa Permanência.

Segundo Camarano e Kanso (2010), as ILPIs são definidas como uma residência coletiva que acolhe tanto idosos independentes ou carentes de renda e/ou família, como também aqueles que possuem dificuldades para realização das atividades diárias, que necessitam de cuidados prolongados. Essas instituições são um dos segmentos mais antigos de atenção ao idoso, porém há a problemática de conduzir essa população ao isolamento e à inatividade física, em consequência do cuidado técnico inapropriado e dos elevados custos desses serviços (REIS; CEOLIM, 2007).

Reis e Ceolim (2007) acrescentam que há um grande déficit no Brasil de programas sociais e de saúde voltados para o idoso, acarretando em muitos casos a internação precoce em ILPIs, levando em conta que esta deveria ser a última opção para os idosos fragilizados e dependentes, que não podem se manter em seus lares. Os estímulos a esses espaços ainda trazem um caráter residual, legitimando a percepção negativa e marginalizada que atravessa sua história dentro da sociedade e do senso comum (CAVALCANTI, 2013). Na medida em que esses idosos vão se fragilizando e adoecendo, as instituições assumem a dupla função: social e de saúde, pois, muitas vezes, os idosos se sentem solitários, sendo levados a desenvolver quadros de angústia e depressão (MICANTO; FREITAS, 2007; AIRES; PAZ; PEROSA, 2006).

Teixeira e Lefèvre (2008) mostram que pesquisas revelam que a espiritualidade em idosos pode ser um fator de enfrentamento perante a doença. $\mathrm{O}$ ato de fé, a confiança e a esperança aumentam, reduzindo o sentimento de angústia e a falta de aceitação. Percebe-se um aumento da fé em Deus na velhice, com meditações em livros bíblicos e maior participação em cultos religiosos. Essa fé do idoso pode ajudar na compreensão das dificuldades perante a vida.

Diante do disposto, o interesse sobre o construto dos valores faz-se importante, pois tem sido correlacionado com diversos fenômenos socio/ psicológicos, entre eles identidade social, bem-estar subjetivo, sentido de vida 
e outros (GOUVEIA et al., 2008; AQUINO, 2009). De forma geral, os valores humanos são compreendidos como construtos que influenciam as atitudes e as ações humanas e servem como padrões avaliativos do comportamento (GOUVEIA, 2003).

A partir da revisão dos principais referenciais teóricos no campo dos valores, Gouveia (1998) pôde verificar que, em geral, os modelos a respeito de valores não apresentam critérios explícitos quanto à identificação da fonte e da natureza desse construto. Logo, sem deixar de reconhecer as contribuições teóricas existentes, Gouveia $(1998 ; 2003)$ desenvolve a Teoria Funcionalista dos Valores Humanos, um modelo que se propõe ser mais parcimonioso e integrador, com padrões de adequabilidade satisfatórios, enfocando as funções dos valores (GOUVEIA, 2003).

O modelo desenvolvido por Gouveia (1998; 2003; 2013) assume cinco pressupostos teóricos principais: (1) natureza benevolente ou positiva dos seres humanos; (2) valores como uma base motivacional, na qual se constituem como representações cognitivas das necessidades dos indivíduos; (3) caráter terminal, visto que expressam um propósito em si; (4) atuação como princípios-guias individuais, ou seja, são compreendidos como padrões gerais de orientação às condutas dos indivíduos, não sendo particulares a uma determinada situação, como ocorrem com as atitudes; e (5) condição perene, que indica que a história é cíclica e que as pessoas não estão sujeitas a um destino imutável.

Gouveia et al. (2009) apontam duas funções consensuais dos valores: eles guiam as ações do homem (tipo orientação) e expressam suas necessidades básicas (tipo motivador) (ROKEACH, 1973; SCHWARTZ, 1992). O tipo de orientação engloba os critérios - também chamados de metas - social (o indivíduo na comunidade), pessoal (o indivíduo por si mesmo) e central (o propósito geral da vida), que juntos compõem o eixo horizontal; e o tipo motivador, por sua vez, é dividido em termos materialistas (pragmáticos), ou seja, as ideias práticas e uma orientação para metas, ou idealistas (abstratos), que são princípios e ideias abstratas e uma orientação universal.

A partir das interações dos valores ao longo dos eixos das duas dimensões valorativas, tipo de orientação e tipo de motivadores, gera-se uma estrutura $3 \times 2$, a qual é composta por seis subfunções, distribuídas de forma equitativa nos critérios de orientação social (interativa e normativa), central (suprapessoal e existência) e pessoal (experimentação e realização) (GOUVEIA, 2013). Dessa forma, nos tipos motivadores materialistas encontram-se as subfunções existência (estabilidade pessoal, saúde e sobrevivência), realização (êxito, poder e prestígio) e normativa (obediência, religiosidade e tradição), e no que diz respeito aos motivadores idealistas há as subfunções suprapessoal (beleza, conhecimento 
e maturidade), experimentação (emoção, prazer e sexo) e interativa (afetividade, apoio social e convivência).

Considera-se especialmente que os valores desempenham um papel importante na percepção do sentido de vida (AQUINO, 2009). Viktor Frankl, no âmbito da Psicologia, compreende a busca de sentido na vida como a motivação primária do ser humano. Mediante esta perspectiva, o sentido é situacional e modifica-se de pessoa para pessoa, manifestando-se sempre na relação do homem com o mundo (AQUINO, 2013).

Ao declarar que o ser humano é um ente responsável e precisa realizar o sentido potencial de sua vida, Frankl (1984) salienta que o sentido deve ser descoberto no mundo, externo ao indivíduo ou de sua psique. Essa característica denomina-se autotranscendência da existência humana, a qual denota o fato de que o ser humano sempre aponta e dirige-se para algo ou alguém diferente de si mesmo, seja um sentido a realizar ou outro ser humano a encontrar. Desse modo, é possível descobrir o sentido na vida a partir de três valores distintos: os valores criativos, onde há a possibilidade de encontrar um sentido no trabalho, ou criando algo para o mundo; os valores vivenciais, que podem ser realizados quando o homem contempla a natureza, as artes ou alguém; e, por fim, os valores atitudinais, que são as atitudes perante o sofrimento inevitável.

Quando ocorre uma perda de sentido ou uma frustração da vontade de sentido, os efeitos não são manifestados apenas em sentimentos de vazio, mas também afetam a base corpórea (LUKAS, 1992). Nesta realidade, estão as pessoas idosas que, quando se aposentam, deixam de exercer uma ocupação, entrando em declínio psicofísico. Assim, podemos destacar outro ângulo bastante pessoal ao indivíduo: a consciência de se ter algo a cumprir, o que mantém o idoso psiquicamente e espiritualmente hígido, preservando-o de doenças e até mesmo da morte (FRANKL, 1990). Dessa forma, perceber um "para quê viver" ou o sentimento de existir para algo ou para alguém se constitui em um valor de sobrevivência (FRANKL, 1990).

Apesar de a morte ser considerada o término da vida biológica (ZIMERMAN, 2000), por muitas vezes ela vem carregada de sentidos negativos e positivos, e os seus significados tentam, em última instância, distanciar o ser humano dessa realidade última (OLIVEIRA; ARAÚJO, 2012). As ideias e crenças religiosas sobre a morte a tornam um fenômeno natural, amenizando sua angústia existencial e, concomitantemente, ajudam o indivíduo a suportar seu desamparo (CONCENTINO; VIANA, 2011).

Estudos sugerem que uma visão negativa da morte está associada a maiores índices de ansiedade perante a mesma (AQUINO et al., 2010). No que se refere ao aspecto emocional, constata-se que a consciência da morte pode 
evocar reações de isolamento, medo ou ressignificação do tempo (GIMENEZ, 2003). Tendo em conta as considerações supracitadas, o presente estudo teve como objetivo identificar o impacto da consciência da finitude na estrutura valorativa nos idosos.

\section{Método}

Trata-se de um estudo de campo correlacional de caráter quantitativo. Nesse tipo de estudo, procura-se encontrar relações entre variáveis e descrever a magnitude de suas correlações.

\subsection{Participantes}

A amostra foi constituída a partir da participação de 50 idosos que residiam em duas Instituições de Longa Permanência para Idosos no município de João Pessoa (PB), com idade média de 76 anos (desvio padrão =9,49), a maioria do sexo feminino (72\%), viúvos (44\%), analfabetos (46\%) e católicos (80\%). Essa foi uma amostra de conveniência (não probabilística), tendo pessoas que se enquadravam nos seguintes critérios: ter idade igual ou superior a 60 anos e não possuir nenhum déficit cognitivo, o que foi informado previamente pelos profissionais responsáveis pelos cuidados dos idosos. 
Tabela 1 - Características sociodemográficas dos participantes $(n=50)$.

\begin{tabular}{lll}
\hline Sexo & Feminino & $72 \%$ \\
& Masculino & $28 \%$ \\
Idade média (dp) & & $76(9,49)$ \\
Escolaridade & Analfabetos & $46 \%$ \\
& Nível Fundamental & $28 \%$ \\
& Nível Médio & $20 \%$ \\
Religião & Nível Superior & $6 \%$ \\
& Católicos & $80 \%$ \\
& Evangélicos & $6 \%$ \\
& Agnósticos & $12 \%$ \\
Estado civil & Ateus & $2 \%$ \\
& Viúvos & $44 \%$ \\
& Solteiros & $28 \%$ \\
& Divorciados & $16 \%$ \\
& Casados & $6 \%$ \\
& Conviventes & $6 \%$ \\
\hline
\end{tabular}

Fonte: Tabela elaborada pelos autores.

\subsection{Instrumentos}

Os participantes responderam a um livreto formado por três instrumentos:

1. Questionário de Valores Básicos (QVB): instrumento elaborado por Gouveia (2003), composto por dezoito itens ou valores específicos. Cada valor é definido por meio de dois descritores, como, por exemplo, saúde: preocupar-se com sua saúde antes mesmo de ficar doente; não estar enfermo; êxito: obter o que se propõe; ser eficiente em tudo que faz; religiosidade: crer em Deus como o salvador da humanidade; cumprir a vontade de Deus; maturidade: sentir que conseguiu alcançar seus objetivos na vida; desenvolver todas as suas capacidades; emoção: desfrutar desafiando o perigo; buscar aventuras; e apoio social: obter ajuda quando a necessite; sentir que não está só no mundo. Os participantes devem indicar a importância que cada valor tem em sua vida, de acordo com uma escala de sete pontos, indicando-se o grau de importância que cada valor tem como um princípio-guia na vida da pessoa, com os seguintes extremos: 1 = Totalmente não importante e 7 = Extremamente importante.

2. Questionário Sentido da Vida (QSV): questionário proposto por Steger et al. (2006) e adaptado para o contexto brasileiro por Aquino et al. (2015). 
O instrumento conta com dois fatores: presença de sentido (por exemplo, "Eu compreendo o sentido da minha vida") e busca de sentido (por exemplo, "Eu estou procurando alguma coisa que faça com que minha vida tenha sentido"), e é formado por dez itens, avaliados em uma escala de 7 pontos, variando de $1=$ Totalmente falso a $7=$ Totalmente verdadeiro.

(QVB sobre a finitude da vida): Retornando ao primeiro instrumento, o QVB (Finitude) foi apresentado com a seguinte instrução: "Agora pensando na sua própria morte, indique o grau de importância para aqueles valores que você gostaria de ter realizado ao chegar ao fim de sua vida. Utilizando a escala de resposta abaixo, indique com um número ao lado de cada valor o grau de importância que este teria como princípio que você consideraria que guiou sua vida ao chegar ao seu término".

Escala de Atitudes Religiosas (EAR-20): instrumento composto por 20 itens, distribuídos em quatro fatores (AQUINO et al., 2013): afetivo (por exemplo, "Extravaso a tristeza ou alegria através de músicas religiosas"; "Sinto-me unido a um 'Ser' maior"); comportamental (por exemplo, "A religião/religiosidade influencia nas minhas decisões sobre o que eu devo fazer"; "Ajo de acordo com o que a minha religião/religiosidade prescreve como sendo correto"); cognitivo (por exemplo, "Leio as escrituras sagradas: bíblia ou outro livro sagrado"; "Costumo ler os livros que falam sobre religiosidade"); e corporeidade (movimentos corporais de expressões religiosas; por exemplo, "Costumo levantar os braços em momentos de louvores"; "Ajoelho-me para fazer minha oração pessoal com Deus"). O participante utiliza uma escala de 5 pontos, com os extremos 1 = Nunca e 5 = Sempre.

Escala de Percepção Ontológica do Tempo (EPOT): escala desenvolvida por Aquino (2009) considerando-se o modelo teórico de Frankl (1989) acerca do sentido da vida, especificamente no que concerne à temporalidade ontológica. Constitui-se um conjunto de dez itens: três para cada uma das perspectivas temporais: passado (por exemplo: "Sinto-me realizado com o que alcancei"), presente (por exemplo: "Vejo sempre um motivo para estar no mundo") e futuro (por exemplo: "Vejo muitas possibilidades de escolha”); e um último, que visa a identificar a satisfação (ou insatisfação) geral com o "eu" ao longo do tempo (por exemplo: "Ao olhar para a minha vida, tenho que admitir que há uma grande distância entre quem eu sou e quem eu poderia ser"). As respostas podem variar em uma escala de 5 pontos entre os extremos $1=$ Discordo totalmente e 5 = Concordo totalmente.

3. Questionário Demográfico: foram incluídas perguntas com a finalidade de caracterizar os participantes do estudo quanto ao sexo, à idade, à escolaridade, ao estado civil e à religião. 
A pesquisa foi submetida à apreciação do Comitê de Ética do Hospital Universitário Lauro Wanderley, da Universidade Federal da Paraíba, João Pessoa (PB), e encontra-se com registro CAAE n.. 30528714.3.0000.5183. Esta pesquisa seguiu os Procedimentos Éticos em Pesquisa com Seres Humanos, como determina a Resolução 466/2012.

A todos foi garantido o caráter voluntário da pesquisa, podendo deixar o estudo a qualquer momento, sem que houvesse penalização. Enfatizou-se que não existiam respostas certas ou erradas e que seria assegurado o anonimato dos participantes, sendo os mesmos advertidos que se tratava de uma pesquisa científica com fins de publicação.

A coleta de dados foi realizada de forma individual, na qual a pesquisadora pontuou as respostas emitidas pelos sujeitos, tendo apresentado os objetivos da pesquisa previamente aos participantes. Quanto à escolha dos participantes, foi realizado previamente um levantamento do déficit cognitivo dos idosos mediante as informações dos profissionais cuidadores das instituições.

\subsection{Análise dos dados}

Utilizou-se o Pacote Estatístico para Ciências Sociais (PAWS, em sua versão 18). Em seguida, foram utilizadas estatísticas descritivas (frequências, médias e desvio padrão), além de Correlação de Pearson e o Teste (t) com o fim de conhecer o poder discriminativo dos itens, bem como a Regressão Linear Múltipla para verificar o nível de relação e em que medida as variáveis antecedentes explicam as variáveis consequentes.

\section{Resultados}

No que se refere à identificação do impacto da consciência da finitude na estrutura valorativa nos idosos, a Tabela 2 sugeriu uma diferença significativa na estrutura valorativa quando a perspectiva da morte é inserida. Destarte, de forma mais específica, constata-se que as médias dos tipos de orientação (pessoal, central e social) reduzem significativamente quando pensadas retrospectivamente tendo em conta a própria mortalidade $(\mathrm{p}<0,001)$. 
Tabela 2 - Médias e desvios padrões dos valores humanos em dois momentos distintos (sem a consciência da morte e com a consciência da morte).

\begin{tabular}{llllllll}
\hline \multicolumn{7}{c}{$\begin{array}{l}\text { Sem a consciência } \\
\text { da morte }\end{array}$} & \multicolumn{3}{l}{$\begin{array}{l}\text { Com a consciência } \\
\text { da morte }\end{array}$} \\
\hline & $\mathrm{m}$ & $\mathrm{dp}$ & $\mathrm{m}$ & $\mathrm{dp}$ & $\mathrm{t}(\mathrm{gl})$ & $\mathrm{p}$ \\
\hline Pessoal & 21,24 & 4,22 & 19,62 & 4,17 & $3,78(49)$ & 0,001 \\
Experimentação & 9,98 & 2,39 & 9,40 & 2,15 & $2,16(49)$ & 0,035 \\
Realização & 11,26 & 2,40 & 10,22 & 2,47 & $3,76(49)$ & 0,001 \\
Central & 27,92 & 3,86 & 21,60 & 5,39 & $12,31(49)$ & 0,001 \\
Suprapessoal & 13,20 & 2,44 & 10,40 & 2,42 & $11,39(49)$ & 0,001 \\
Existência & 14,72 & 2,01 & 11,20 & 3,23 & $9,83(49)$ & 0,001 \\
& & & & & & \\
Social & 29,40 & 4,20 & 23,66 & 5,78 & $9,20(49)$ & 0,001 \\
Interativa & 14,72 & 2,23 & 11,72 & 3,19 & $7,85(49)$ & 0,001 \\
Normativa & 14,68 & 2,40 & 11,94 & 2,92 & $8,52(49)$ & 0,001 \\
\hline
\end{tabular}

Fonte: Elaborada pelos autores.

Com relação ao segundo objetivo, o de averiguar a relação entre a percepção ontológica do tempo (passado, presente e futuro) e a atitude religiosa dos idosos, constatou-se que a percepção de sentido no presente se associou significativamente com o conhecimento $(\mathrm{r}=0,42, \mathrm{p}<0,01)$, o comportamento $(\mathrm{r}=0,43, \mathrm{p}<0,01)$, o sentimento $(\mathrm{r}=0,38, \mathrm{p}<0,01)$ e a corporeidade religiosa $(\mathrm{r}=0,43, \mathrm{p}<0,01)$. No que se refere ao passado, apenas a corporeidade se associou com essa variável $(\mathrm{r}=0,31, \mathrm{p}<0,05)$. Por fim, no que tange ao futuro, tanto o conhecimento religioso $(r=0,34, p<0,05)$ quanto o comportamento religioso se correlacionaram com esse fator. 
Tabela 3 - Correlação da percepção ontológica do tempo com a atitude religiosa.

\begin{tabular}{llll}
\hline & Passado & Presente & Futuro \\
\hline Conhecimento religioso & 0,08 & $0,42^{\star \star}$ & $0,45^{\star \star}$ \\
Comportamento religioso & 0,16 & $0,43^{\star \star}$ & $0,34^{\star}$ \\
Sentimento religioso & 0,23 & $0,38^{\star \star}$ & 0,21 \\
Corporeidade religiosa & $0,31^{\star}$ & $0,43^{\star \star}$ & 0,24 \\
\hline
\end{tabular}

Fonte: Elaborada pelos autores.

${ }^{\star} p<0,05 ;{ }^{* \star} p<0,01$.

O terceiro objetivo foi o de verificar as relações entre o sentido na vida e a atitude religiosa dos idosos. Os resultados sugerem que a presença de sentido se correlaciona com conhecimento $(r=0,44, p<0,01)$, comportamento $(\mathrm{r}=0,28, \mathrm{p}<0,05)$ e sentimento $(\mathrm{r}=0,28, \mathrm{p}<0,05)$. Já a busca de sentido se associa diretamente com o conhecimento religioso $(r=0,48, p<0,01)$ e com a corporeidade religiosa $(r=0,30, p<0,05)$.

Tabela 4 - Correlação entre o sentido na vida e a atitude religiosa.

\begin{tabular}{lll}
\hline & Presença de sentido & Busca de sentido \\
\hline Conhecimento religioso & $0,44^{* *}$ & $0,48^{* *}$ \\
Comportamento religioso & $0,28^{*}$ & 0,33 \\
Sentimento religioso & $0,28^{*}$ & 0,19 \\
Corporeidade religiosa & 0,14 & $0,30^{*}$ \\
\hline
\end{tabular}

Fonte: Elaborada pelos autores.

${ }^{*} \mathrm{p}<0,05$; ${ }^{* *} \mathrm{p}<0,01$.

Utilizando-se variáveis dependentes, como a presença e a busca de sentido, foram testados, por meio de uma regressão múltipla, dois modelos que levam em conta como preditores as variáveis percepção ontológica do tempo, atitudes religiosas e valores humanos (Tabela 5). 
Tabela 5 - Regressão Linear (stepwise) tendo como variável o critério "presença e busca de sentido" em idosos em Instituições de Longa Permanência.

\begin{tabular}{|c|c|c|c|c|}
\hline & Preditores & $B$ & $\mathrm{t}$ & $p$ \\
\hline \multirow[t]{3}{*}{ Presença de sentido } & Percepção do presente & 0,40 & 3,16 & 0,003 \\
\hline & Subfunção existência & 0,34 & 2,68 & 0,010 \\
\hline & $\mathrm{R}^{2}=0,40 ; \mathrm{R}^{2}$ austado $=0,37$ & & & \\
\hline \multirow[t]{3}{*}{ Busca de sentido } & Conhecimento religioso & 0,40 & 3,33 & 0,002 \\
\hline & Subfunção suprapessoal & 0,38 & 3,16 & 0,003 \\
\hline & $R^{2}=0,37 ; R^{2}$ austado $=0,34$ & & & \\
\hline
\end{tabular}

Fonte: Elaborada pelos autores.

Na tabela 4, pode-se compreender o impacto das variáveis nos dois modelos considerados. Modelo 1, com índice de correlação múltipla de $[\mathrm{F}(2)=247,68$; $p<0,001]$, sugeriu que as contribuições significativas para explicar a presença de sentido foram as variáveis percepção do presente $(\beta=0,40)$ e a subfunção existência $(\beta=0,34)$, que juntas explicaram $37 \%$ da variância. Tal modelo se apresentou mais adequado. Já o modelo 2, que apresentou o índice de correlação múltipla de $\mathrm{F}(2)=13,48 ; \mathrm{p}<0,001$, indicou que tanto o conhecimento religioso $(\beta=0,40)$ quanto a subfunção suprapessoal $(\beta=0,38)$ contribuem juntas com $34 \%$ da variância para explicar a busca de sentido.

\section{Discussão}

Diante dos resultados, ocorreram mudanças na estrutura valorativa quando colocadas diante da finitude. Sabe-se que, com a velhice, a morte torna-se mais saliente. Dessa maneira, quando o ser humano tem a consciência da finitude, começa a entender o dinamismo da vida e sofre a inclinação de rever seus valores (ARAÚJO et al., 2013).

No que se refere às variáveis atitudes religiosas e percepção ontológica do tempo, identificou-se que a percepção de sentido no presente se associou positivamente com todos os componentes da atitude religiosa (conhecimento, comportamento, sentimento e corporeidade). Percebe-se que os idosos encontram sentido na vivência da religiosidade, sendo uma forma de enfrentamento para as questões existenciais que são emergentes nesse período da vida (AQUINO et al., 2009).

Indubitavelmente, a explicação da mudança dos valores em decorrência da consciência da finitude deve estar relacionada à variação nas prioridades 
valorativas. Segundo a compreensão de Frankl (1989), a morte dá sentido à vida, posto que nesses casos o ser humano se preocupa com os valores que podem ser fontes de sentidos. Entretanto, quando os idosos são convidados a pensar na própria morte e avaliar os valores que gostariam de ter realizado ao chegar ao fim de suas vidas, ocorre uma baixa nos escores médios das subfunções valorativas. Possivelmente, os valores humanos nesse cenário já não são mais objetos de preocupação, já que não se encontram mais disponíveis como possibilidades.

Nessa perspectiva, Cótica (2011) analisou a percepção do envelhecimento e finitude em idosos no projeto Melhor Idade no município de Paraíso do Tocantins. Analisados de forma qualitativa, foram usados três instrumentos: entrevista semiestruturada, escala de ansiedade perante a morte e questionário de ansiedade perante a morte. Quanto aos resultados encontrados sobre o medo da ideia de morrer, a maioria dos entrevistados (75\%) afirmou não se assustar com essa possibilidade, mesmo sabendo que nessa fase de suas vidas o risco de morte é cada vez maior. Ou seja, o medo de envelhecer não se resume apenas na finitude humana, mas além, como a propensão de doenças crônicas e a solidão.

Segundo Frankl (1989), aparentemente, a morte retira o sentido da vida humana. A transitoriedade da existência, de maneira evidente, faz perder o sentido, pois ela constitui a essência da responsabilidade humana. O ser humano está sempre buscando alternativas diante da massa de potencialidades existentes. Portanto, quais serão condenadas e quais serão concretizadas dependem da liberdade e da responsabilidade do indivíduo. Dessa forma, na morte, o ser humano se converte em seu próprio passado, ou seja, em suas escolhas efetivadas em sua existência (FRANKL, 1984).

No que tange à perspectiva do passado, apenas a corporeidade religiosa se relacionou com essa variável. Compreende-se que os idosos que se sentem mais realizados apresentam uma maior expressão religiosa. Nessa perspectiva, a religiosidade poderia ter uma função catalisadora de perceber o passado de forma mais integrada.

Em relação à percepção do futuro, apenas duas subescalas de religiosidade se associaram diretamente (conhecimento e comportamento religioso). Goldstein e Neri (2000) ressaltam a dimensão da religiosidade que envolve crenças, valores, atitudes. Em sua pesquisa, ao investigarem religiosidade em sua dimensão objetiva e subjetiva relacionada à satisfação na vida de pessoas adultas e idosas, destacaram a diferença entre religiosidade intrínseca e extrínseca, sendo a intrínseca o indivíduo que internalizou suas crenças de modo que a mesma faz parte da sua vida cotidiana. 
O presente estudo sugeriu uma relação entre a presença de sentido e os componentes da atitude religiosa (conhecimento, comportamento e sentimento religioso). Frankl ressalta que o ser humano saudável deve estar voltado para algo ou alguém em forma de um "tu". Dessa forma, a religiosidade pode ser uma expressão genuína desse caráter antropológico (autotranscendência), tendo em conta que, para o homem religioso, o Deus pessoal seria interpretado como um ente transcendente (FRANKL, 2011). Nessa linha de raciocínio, a fé religiosa surge como uma crença no suprassentido, visto que a religiosidade só é autêntica quando é existencial, espontânea, ou seja, quando o ser humano escolhe livremente perante quem ele se considera responsável (AQUINO, 2014).

Já em relação à busca de sentido, esta se associou com o conhecimento e a corporeidade religiosa. Frankl fala dessa concepção, na qual o indivíduo possui uma essência, a soma do corpo com a psique, e essa dimensão ética/ espiritual é compreendida mais como uma dimensão antropológica do que religiosa. Sendo assim, ele considera que a maneira de abordar o ser humano é compreendê-lo de forma integral (AQUINO, 2013).

O estudo também procurou identificar os preditores da presença de sentido e da busca de sentido. No que se refere à presença, esta foi determinada por duas variáveis. A primeira foi a subfunção existência, que é representada por meio de valores como saúde, sobrevivência e estabilidade pessoal. Tais valores são adotados por pessoas que vivem em ambientes ameaçadores, recursos econômicos escassos e sem segurança econômica (GOUVEIA, 2013), como é o caso das ILPIs. A segunda variável foi a percepção do presente (ver motivos para estar no mundo, realizar tarefas significativas e encontrar uma razão para levantar-se da cama pela manhã).

Já a busca de sentido foi influenciada pelo conhecimento religioso (ler livros religiosos, procurar conhecer as doutrinas, assistir a programas religiosos, etc.) e pela subfunção suprapessoal (representada por valores como conhecimento, maturidade e beleza), típicos de pessoas mais velhas e maduras (VIONE, 2012). Essa condição constitui-se a partir da autotranscendência, do voltar-se para algo que transcenda o próprio "eu". Nessa perspectiva, esse achado sugere que os programas preventivos em idosos institucionalizados possam promover a busca de sentido por meio dos valores de contemplação e busca de conhecimentos que possam atuar como catalisadores da procura de significados para o presente e para o futuro. 
A questão do sentido compreende não apenas o nascimento (de onde eu vim) e a morte (para onde vou), mas se constitui e se fundamenta na temporalidade, no passado, no presente e no futuro. Assim, buscou-se compreender as relações entre a percepção ontológica do tempo e a atitude religiosa nos idosos, bem como as associações entre o sentido da vida e a atitude religiosa. O presente estudo pôde constatar a importância da religiosidade na ressignificação da existência, desvelando que os idosos constituem uma compreensão ontológica ancorada em uma cosmovisão religiosa, que tem por função ajudar a busca de sentido.

Diante de todos os resultados encontrados no estudo e frente ao aporte teórico pesquisado, o envelhecimento imerge nas diversas dimensões do indivíduo, sendo importante analisar objetivamente esses aspectos, norteando possíveis programas à promoção de sentido nessa fase da vida. Desse modo, tanto a religiosidade quanto os valores humanos podem representar importantes fatores para que esses idosos encontrem maior sensação de sentido na vida. Por conseguinte, compete aos profissionais de saúde uma compreensão mais ampla dos fatores de proteção, promovendo intervenções que venham ajudar os idosos que vivem nessas instituições, com terapêuticas que incluam questões existenciais, abarcando, assim, a totalidade da condição humana.

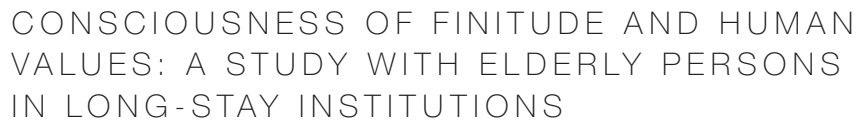

This work has had as primary purpose to identify the impact of the consciousness of finitude in elderly's structure of values. A total of 50 elderly individuals, residents of long-stay institutions, most of them women (72\%), with an average age of 76 years of age, in most part catholic (80\%), took part in this study. The instruments of data collection were Basic Values Questionnaire (BVQ), Meaning in Life Questionnaire (MLQ), Religious Attitudes Scale (RAS-20), Ontological Time Perception Scale (OTPS) and a sociodemographic questionnaire. The results have been discussed according to the Logotherapy and Existential Analysis by Viktor Frankl, relating the consciousness of finitude to the structure of values, the ontological time perception, the religious attitude and the temporality perception in the pursuit and presence of meaning. 
referências

AIRES, Marinês; PAZ, Adriana Aparecida; PEROSA, Cleci Terezinha. O grau de dependência e características de pessoas idosas institucionalizadas. Revista Brasileira de Ciências do Envelhecimento Humano, Passo Fundo, v. 3, n. 2, p. 79-91, jul./dez. 2006.

AQUINO, Thiago Antônio Avellar de. A presença ignorada de Deus na obra de Viktor Frankl. São Paulo: Paulus, 2014.

Atitudes e intenções de cometer suicídio: seus correlatos existenciais e normativos. 2009. 259 f. Tese (Doutorado em Psicologia)-Universidade Federal da Paraíba, João Pessoa, 2009.

Logoterapia e Análise Existencial: uma introdução ao pensamento de Viktor Frankl. São Paulo: Paulus, 2013.

AQUINO, Thiago Antônio Avellar de et al. Atitude religiosa e sentido da vida: um estudo correlacional. Psicologia: Ciência e Profissão, Brasília, v. 29, n. 2, p. 228-243, jun. 2009.

Escala de Atitudes Religiosas, versão expandida (EAR-20): evidências de

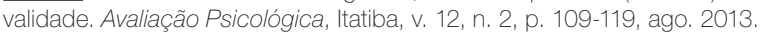

Questionário de Sentido de Vida: evidências de sua validade fatorial e consistência interna. Psicologia: Ciência e Profissão, Brasília, v. 35, n. 1, p. 4-19, jan./mar. 2015.

Visões de morte, ansiedade e sentido da vida: um estudo correlacional. Psicologia Argumento, Curitiba, v. 28, n. 63, p. 289-302, out./dez. 2010.

ARAÚJO, Camila da Cruz Ramos de et al. Influência da idade na percepção de finitude e qualidade de vida. Ciência \& Saúde Coletiva, Rio de Janeiro, v. 18, n. 9, p. 2497-2505, set. 2013.

CAMARANO, Ana Amélia; KANSO, Solange. As Instituições de Longa Permanência para Idosos no Brasil. Revista Brasileira de Estudos de População, Rio de Janeiro, v. 27, n. 1, p. 233-235, jan./jun. 2010.

CAVALCANTI, Alana Diniz. Envelhecimento e institucionalização: uma revisão bibliográfica à luz da promoção da saúde. Revista Kairós Gerontologia, São Paulo, v. 16, n. 4, p. 159-174, 2013.

CONCENTINO, Jamille Mamed Bonfim; VIANA, Terezinha de Camargo. A velhice e a morte: reflexões sobre o processo de luto. Revista Brasileira de Geriatria e Gerontologia, Rio de Janeiro, v. 14, n. 3, p. 591-599, 2011.

CÓTICA, Carolina Santin. Percepção de envelhecimento e finitude no final da vida adulta tardia. Revista Brasileira de Geriatria e Gerontologia, Rio de Janeiro, v. 5, n. 4 , p. 201-213, ago. 2011.

FIGUEIREDO, Nébia Maria Almeida de; TONINI, Teresa. Gerontologia: atuação da Enfermagem no processo de envelhecimento. 2. ed. São Paulo: Yendis, 2006.

FRANKL, Viktor Emil. A vontade de sentido: fundamentos da Logoterapia e aplicações da Logoterapia. São Paulo: Paulus, 2011.

Em busca de sentido: um psicólogo no campo de concentração. 37. ed. Petrópolis: Vozes; São Leopoldo: Sinodal, 1984. 
Psicoterapia para todos: uma psicoterapia coletiva para contrapor-se à neurose coletiva. Petrópolis: Vozes, 1990. v. 1.

GIMENEZ, Maria da Glória Gonçalves. A passagem entre a vida e a morte: uma perspectiva psico-espiritual em cuidados paliativos domiciliares. O Mundo da Saúde, São Paulo, v. 27, n. 1, p. 153-158, jan./mar. 2003

GOLDSTEIN, Lucila; NERI, Anita. Tudo bem, graças a Deus: religiosidade e satisfação na maturidade. In: NERI, Anita (Org.). Qualidade de vida e idade madura. Campinas: Papirus, 2000. p. 109-136.

GOUVEIA, Valdiney. A natureza motivacional dos valores humanos: evidências acerca de uma nova tipologia. Estudos de Psicologia, Natal, v. 8, n. 3, p. 431-444, set./dez. 2003.

- La naturaleza de los valores descriptores del individualismo y del colectivismo: una comparación intra e intercultural. 1998. 450 f. Tese (Doutorado em Psicologia Social)-Universidade Complutense de Madrid, Madrid, 1998

Teoria funcionalista dos valores humanos: fundamentos, aplicações e perspectivas. São Paulo: Casa do Psicólogo, 2013.

GOUVEIA, Valdiney et al. Teoria funcionalista dos valores humanos. In: TEIXEIRA, Maria Luisa (Ed.). Valores humanos e gestão: novas perspectivas. São Paulo: Senac, 2008. p. $47-80$

Teoria funcionalista dos valores humanos: aplicações para organizações. Revista de Administração Mackenzie, São Paulo, v. 10, n. 3, maio/jun. 2009.

LUKAS, Elisabeth. Prevenção psicológica: a prevenção de crises e a proteção do mundo interior do ponto de vista da Logoterapia. Petrópolis; São Leopoldo: Vozes, 1992.

MICANTO, Paula Cristina; FREITAS, Cintia de La Rocha. Qualidade de vida dos idosos residentes em instituições asilares da cidade de Caxias do Sul - RS. Revista Brasileira de Ciências do Envelhecimento Humano, Passo Fundo, v. 4, n. 1, p. 127-138, jan./jun. 2007.

OLIVEIRA, Sandra Carolina Farias de; ARAÚJO, Ludgleydson Fernandes. A finitude na perspectiva de homens idosos: um estudo das representações sociais. Revista Kairós Gerontologia, São Paulo, v. 15, n. 4, p. 66-83, ago. 2012.

REIS, Priscilleyne Ouverney; CEOLIM, Maria Filomena. O significado atribuído a "ser idoso" por trabalhadores de Instituições de Longa Permanência. Revista da Escola de Enfermagem da USP, São Paulo, v. 41, n. 1, p. 57-64, 2007.

ROKEACH, Milton. The nature of human values. New York: Free Press, 1973.

SCHWARTZ, Shalom. Universals in the content and structure of values: theoretical advances and empirical tests in 20 countries. In: ZANNA, Mark (Org.). Advances in experimental social psychology. New York: Academic Press, 1992. v. 25. p. 1-65.

SILVA, Antônio Itamar da; ALVES, Vicente Paulo. Envelhecimento: resiliência e espiritualidade. Diálogos Possíveis, Salvador, v. 6, n. 1, p. 189-209, jan./jun. 2007.

STEGER, Michael et al. The Meaning in Life Questionnaire: assessing the presence of and search for meaning in life. Journal of Counseling Psychology, Washington, DC, v. 53, n. 1, p. 80-93, 2006 
TEIXEIRA, Jorge; LEFÈVRE, Fernando. Significado da intervenção médica e da fé religiosa para o paciente idoso com câncer. Ciência \& Saúde Coletiva, Rio de Janeiro, v. 13, n. 4, p. $1247-1256,2008$.

VIONE, Katia Corrêa. As prioridades valorativas mudam com a idade? Testando as hipóteses de rigidez e plasticidade. 2012. 152 f. Dissertação (Mestrado em Psicologia)-Universidade Federal da Paraíba, João Pessoa, 2012.

ZIMERMAN, Guiti. Velhice: aspectos biopsicossociais. Porto Alegre: Artemed, 2000

Data de Submissão: 31/08/2017

Data de Aprovação: 20/09/2018 
